\title{
Biomarkers of Oxidative with Colorectal Cancer
}

\section{Mustapha HADDOUCHE*}

Laboratory of Applied Molecular Biology and Immunology, Abou-Bekr University Belkaid Tlemcen 13000. ALGERIA

${ }^{*}$ Corresponding author: Dr. Mustapha Haddouche, Laboratory of Applied Molecular Biology and Immunology BIOMOLIM, Department of Biology, University of Abou-Bekr Belkaid, Tlemcen 22, Abi Ayed Abdelkrim street, BP 119, Faubourg Pasteur13000 Tlemcen, Algeria; E-mail: haddouchemustapha2004@yahoo.fr

Received: February 08, 2020; Accepted: February 10, 2020; Published: February 19, 2020

\begin{abstract}
The number of colorectal cancer increases regularly every year in Algeria and precisely in Tlemcen. It is a disease involving several genetic, hormonal, professional, environmental, but also behavioral factors, namely nutrition, the objective is to evaluate the nutritional and lipid profile on the one hand and some oxidative parameters of And to determine the relationship that may exist between nutritional factors and oxidative stress in patients with this type of cancer.
\end{abstract}

Keywords: Oxidative Stress, Colorectal Cancer

\section{Materials and Methods}

Thirty-three patients with newly diagnosed colorectal cancer were recruited from the Department of Gastroenterology, C.H.U. (CL, HDL-LC, LDL-CL, TG) and the oxidative status (ORAC, Catalase, Vitamin C, MDA) of Tlemcen and thirty-five healthy controls.

\section{Results}

A very significant difference was observed for patients with liver cancer compared to ORAC controls $(1,143 \pm 0.121)(0,4197 \pm 0.0456)$ $\mathrm{p}<0.000 ; \operatorname{MDA}(0,2400 \pm 0.0492)(0,083 \pm 0.0275) \mathrm{P}<0.008$; Catalase $(1.385 \pm 0.162)(0,588 \pm 0.219) \mathrm{p}<0.008$; LDL-CHOL $(0.4300 \pm$ $0.0239)(1.0692 \pm 0.0627 \mathrm{p}<0.000$, on the other hand no difference was observed for Vitamin $C(0.221 \pm 0.0465)(0,1947 \pm 0.0889) \mathrm{p}$ $<0.615$ HDL-CHOL $(0.4300 \pm 0.0322)(0.466 \pm 0.031) \mathrm{p}<0.355$.

The balance of the oxidizing / antioxidant status is a primary factor in oncology. The free radicals can lead to the appearance of mutations and, conversely.

\section{References}

1. Golbidi S, Laher I (2010) Antioxidant therapy in human endocrine disorders. Med Sci Monit 16: 9-24.

2. Jaeschke H (2011) Reactive oxygen and mechanisms of inflammatory liver injury: Present concepts. J Gastroenterol Hepatol 1: 173-179. [Crossref] 